\title{
Melanin Biosynthesis Inhibitory Activity of Compounds Isolated from Unused Parts of Ammi visinaga
}

\author{
Ahmed Ashour ${ }^{1,2}$, Saleh El-Sharkawy ${ }^{2,3}$, Mohamed Amer ${ }^{2}$, Fatma Abdel Bar ${ }^{2}$, Ryuichiro Kondo ${ }^{1}$, \\ Kuniyoshi Shimizu ${ }^{{ }^{*}}$ \\ ${ }^{1}$ Department of Agro-Environmental Sciences, Faculty of Agriculture, Kyushu University, Fukuoka, Japan; ${ }^{2}$ Department of Pharma- \\ cognosy, Faculty of Pharmacy, Mansoura University, Mansoura, Egypt; ${ }^{3}$ Department of Pharmacognosy, Faculty of Pharmacy, Delta \\ University for Science and Technology, Mansoura, Egypt. \\ Email: *shimizu@agr.kyushu-u.ac.jp
}

Received October $17^{\text {th }}, 2013$; revised November $10^{\text {th }}, 2013$; accepted November $17^{\text {th }}, 2013$

Copyright (C) 2013 Ahmed Ashour et al. This is an open access article distributed under the Creative Commons Attribution License, which permits unrestricted use, distribution, and reproduction in any medium, provided the original work is properly cited.

\begin{abstract}
Ten compounds have been isolated from the unused parts of Ammi visinaga. The isolated compounds were identified as tetracosanoic acid (1), $\beta$-sitosterol (2), visnadine (3), khellin (4), $\beta$-sitosterol glucoside (5), norkhellol (6), khellol (7), rhamnazin (8), cimifugin (9), and cis-khellactone-3'- $\beta$-glucopyranoside (10). The chemical structures of these compounds were elucidated based on spectroscopic data (NMR, UV, MS and IR spectra). This is the first report on the identification of tetracosanoic acid (1), norkhellol (6) and cimifugin (9) in the Ammi genus. The melanin biosynthesis inhibitory activities of khellin (4), khellol (7), visnadine (3), cimifugin (9), $\beta$-sitosterol (2) and $\beta$-sitosterol glucoside (5) were evaluated. Khellin (4) exhibited a potent melanin inhibitory effect compared to arbutin with less toxicity.
\end{abstract}

Keywords: Ammi visinaga; Khellin; Melanin

\section{Introduction}

Natural products derived from plant sources have been used extensively in traditional medicine for treatment of a myriad of diseases including various types of cancers [1]. Further evidence of the importance of natural products is provided by the fact that close to half of the best selling pharmaceuticals in 1991 were either natural products or their derivatives [2].

A. visinaga is a perennial herb widely distributed in the Mediterranean area. Among Egyptians people, it is called Khilla, Chellah or Kella, while in Europe the plant has often been referred to as the Toothpick Herb or Bishop's weed [3]. Turkish people referred to this plant as "disotu", "kilir", and "hiltan" [4].

A. visinaga extracts have demonstrated to have a broad range of therapeutic effects such as antihyperglycemic [5], vasodilator effect [6], anti-inflammatory [7], and inhibition of oxalate nephrlithiasis [8].

Previous phytochemical studies on Ammi genus have reported the presence of naphthoquinones, naphtopyranes, steroid, triterpene and flavanoid [4,9-11]. Mostly these

${ }^{*}$ Corresponding author. phytochemical studies were done on A. visinaga fruit which is the official part of the plant, however little phytochemical studies were found concerning other parts of the plant, so this research was conducted to isolate the chemical constituents of the unused parts of $A$. visinaga and evaluate its potential use in pharmacy and medicine.

\section{Material and Methods}

\subsection{Reagents}

$\mathrm{NaOH}$ and DMSO were purchased from Wako Pure Chemical Industries, Ltd. (Osaka, Japan). The 3-(4,5dimethyl-thiazol-2-yl)-2,5-diphenyl tetrazolium bromide (MTT) from Sigma (St. Louis, MO), EMEM from Nissui Chemical Co (Osaka, Japan). Other chemicals are of the highest grade commercially available.

\subsection{Plant Material}

A visinaga waste represented by all the aerial parts except the fruit was collected in May 2011 from crops grown at Faculty of Pharmacy fields. The plant was identified by Prof. Ibrahim Mashaly, Systematic Botany De- 
partment, Faculty of Sciences, Mansoura University. A voucher specimen (No. 865) is kept in Pharmacognosy Department, Faculty of Pharmacy, Mansoura University.

\subsection{Extraction and Isolation Procedures}

Dried powdered plant $(2.5 \mathrm{~kg})$ was percolated with $\mathrm{MeOH}$ till exhaustion at room temperature. The combined extracts were collected and evaporated to dryness under reduced pressure at $40^{\circ} \mathrm{C}$. The residue, $273 \mathrm{~g}$, was suspended in distilled water and extracted successively with pet. ether, methylene chloride and EtOAc. The different extracts were evaporated under reduced pressure to obtain pet. ether fraction (fraction A, $48 \mathrm{~g}$ ), methylene chloride fraction (fraction $\mathrm{B}, 50 \mathrm{~g}$ ) and EtOAc fraction (fraction $\mathrm{C}, 10 \mathrm{~g}$ ).

\subsection{Isolation of Compounds}

Fraction A was dissolved totally in the smallest volume of methylene chloride $(75 \mathrm{~mL})$ and then mixed well with about $30 \mathrm{~g}$ silica gel and left at room temperature to dry and applied onto the top of a silica gel packed glass column $(65 \times 4.5 \mathrm{~cm}, 420 \mathrm{~g})$, previously packed in petroleum ether. Elution started with petroleum ether $(2 \mathrm{~L})$, then using petroleum ether/ethyl acetate $[2 \% / 98 \%(7 \mathrm{~L})$, 3/97 (4 L), 5/95 (7.5 L), 9/91 (1.5 L), 11/89 (1.5 L), $15 / 85(1.5 \mathrm{~L}), 20 / 80(3 \mathrm{~L}), 25 / 75(0.5 \mathrm{~L}), 30 / 70(3.5 \mathrm{~L})$, $35 / 65(6 \mathrm{~L}), 40 / 60(1 \mathrm{~L}), 60 / 40(4 \mathrm{~L})]$ and finally washed with $100 \%$ ethyl acetate. Effluents, $200 \mathrm{~mL}$ fraction each, were separately concentrated, monitored by TLC plates in solvent system $5 \%-40 \% \mathrm{v} / \mathrm{v}$ petroleum ether/ethyl acetate, and the developed TLC were heated after spraying with vanillin/sulfuric acid spray reagent. Similar fractions were pooled in order to be subjected for further chromatographic separation and purification. These fractions are purified by chromatographic and repeated crystallization methods to afford tetracosanoic acid $(1,12$ $\mathrm{mg}), \beta$-sitosterol $(2,750 \mathrm{mg})$, visnadine $(3,500 \mathrm{mg})$, khellin $(4,800 \mathrm{mg})$ and $\beta$-sitosterol glucoside $(5,270$ $\mathrm{mg}$ ).

Fraction B was dissolved totally in the smallest volume of methanol and then mixed well with about $30 \mathrm{~g}$ silica gel and left at room temperature to dry and applied onto the top of a silica gel packed glass column $(70 \times 4.5$ $\mathrm{cm}, 450 \mathrm{~g}$ ), previously packed in petroleum ether and developed by gradient elution using petroleum ether/ ethyl acetate $[2 \% / 98 \%(1.5 \mathrm{~L}), 5 / 95(2 \mathrm{~L}), 10 / 90(2 \mathrm{~L})$, 20/80 (7 L), 25/75 (1 L), 30/70 (8 L), 35/65 (2 L), 40/60 (1.5 L), 50/50 (6 L), 60/40 (3 L), 80/20 (0.5 L), 100/0 (4 L)], then the elution was continued using methanol/ethyl acetate $[5 \% / 95 \%(4 \mathrm{~L}), 20 / 80(1 \mathrm{~L}), 35 / 65(1 \mathrm{~L})]$ and finally washed with $100 \%$ methanol. The effluents, 200 $\mathrm{mL}$ fraction each, were separately concentrated, monitored by TLC plates in solvent system $20 \%$ - $90 \%$ ethyl acetate/petroleum ether, and the developed TLC were heated with vanillin/sulfuric spray reagent. Similar fractions were pooled, concentrated and subjected to chromatographic separation and purification. These fractions are purified by chromatographic and repeated crystallization methods to afford norkhellol (6, $7 \mathrm{mg})$, khellol (7, 14 $\mathrm{mg})$, rhamnazin $(8,6 \mathrm{mg})$, cimifugin $(9,9 \mathrm{mg})$ and cis-khellactone-3'- $\beta$-glucopyranoside $(10,9 \mathrm{mg})$.

Fraction $\mathrm{C}$ was dissolved totally in the smallest volume of methanol and then mixed well with about $9 \mathrm{~g}$ silica gel and left at room temperature to dry and applied onto the top of a silica gel packed glass column $(60 \times 4.5$ $\mathrm{cm}, 325 \mathrm{~g}$ ), previously packed in petroleum ether and developed by gradient elution using petroleum ether/ ethyl acetate $[10 \% / 90 \%(2.5 \mathrm{~L}), 15 / 85(2 \mathrm{~L}), 25 / 75(3 \mathrm{~L})$, 30/70 (2 L), 35/65 (3 L), 40/60 (1 L), 50/50 (2 L), 60/40 $(2 \mathrm{~L}), 70 / 30(1 \mathrm{~L}), 80 / 20(1 \mathrm{~L}), 90 / 10(1 \mathrm{~L}), 100 / 0(0.5$ L)], then the elution was continued using methanol/ethyl acetate $[5 \% / 95 \%(0.5 \mathrm{~L}), 10 / 90(2 \mathrm{~L}), 30 / 70(1.5 \mathrm{~L})$, $50 / 50(2 \mathrm{~L}), 70 / 30(1 \mathrm{~L})]$ and finally washed with $100 \%$ methanol. The effluents, $200 \mathrm{~mL}$ fraction each, were separately concentrated, monitored by TLC plates in solvent system 30\% - 90\% ethyl acetate/petroleum ether, and the developed TLC were heated with vanillin/sulfuric spray reagent. Similar fractions were pooled, concentrated and subjected to chromatographic separation and purification. These fractions are purified by chromatographic and repeated crystallization methods to afford visnadine $(3,14 \mathrm{mg})$, khellol $(7,2 \mathrm{mg})$ which were previously isolated from other fractions.

\subsection{Cell Line}

A mouse melanoma cell line, B16, was obtained from RIKEN Cell Bank. The cells were maintained in EMEM supplemented with $10 \%(\mathrm{v} / \mathrm{v})$ fetal bovine serum (FBS) and $0.09 \mathrm{mg} / \mathrm{mL}$ theophylline. The cells were incubated at $37^{\circ} \mathrm{C}$ in a humidified atmosphere of $5 \% \mathrm{CO}_{2}$.

\subsection{B16 Melanoma Cell Line Assay}

This assay was determined as described previously [12]. The cells were placed in two plates of 24 -well plastic culture plates (one plate for determining melanin and the other for cell viability) at a density of $1 \times 10^{5}$ cells/well and incubated for $24 \mathrm{~h}$ in media prior to being treated with the samples. After $24 \mathrm{~h}$, the media were replaced with $998 \mu \mathrm{L}$ of fresh media and $2 \mu \mathrm{L}$ of the test sample at maximum solubility $(n=3)$. At the same time, negative control (2 $\mu \mathrm{L}$ DMSO) and positive control; Arbutin at concentration $50 \mathrm{mg} / \mathrm{mL}$ in DMSO were tested. The cells were incubated for an additional $48 \mathrm{~h}$, and then the medium was replaced with fresh medium containing each sample. After $24 \mathrm{~h}$, the remaining adherent cells were assayed. To determine the melanin content (for one plate) 
after removing the medium and washing the cells with PBS, the cell pellet was dissolved in $1.0 \mathrm{~mL}$ of $1 \mathrm{~N}$ $\mathrm{NaOH}$. After overnight keeping in dark, the crude cell extracts were assayed by using a microplate reader at 405 $\mathrm{nm}$ to determine the melanin content. The results from the cells treated with the test samples were analyzed as a percentage of the results from the control culture. On the other hand, cell viability was determined by using MTT assay which provides a quantitative measure of the number of viable cells by determining the amount of formazan crystals produced by metabolic activity in treated versus control cells. So, for the other well plate, $50 \mu \mathrm{L}$ of MTT reagent in PBS $(5 \mathrm{mg} / \mathrm{mL})$ was added to each well. The plates were incubated in a humidified atmosphere of $5 \%$ of $\mathrm{CO}_{2}$ at $37^{\circ} \mathrm{C}$ for $4 \mathrm{~h}$. After the medium was removed, $1.0 \mathrm{~mL}$ isopropyl alcohol (containing $0.04 \mathrm{~N} \mathrm{HCl}$ ) was added, and the absorbance was measured at $570 \mathrm{~nm}$ after overnight keeping in dark.

\section{Results and Discussion}

Ten compounds have been isolated from the aerial parts (except fruit) of $A$. visinaga. They were identified by comparative study to those cited in the literature [13-18]. These compounds (Figure 1) are tetracosanoic acid (1), $\beta$-sitosterol (2), visnadine (3), khelllin (4), $\beta$-sitosterol glucoside (5), norkhellol (6), khellol (7), rhmnazin (8), cimifugin (9) and cis-khellactone-3'- $\beta$-glucopyranoside (10).

\section{Biological Activity}

In ancient Egypt, vitiligo lesions were treated with extracts of the Ammi genus plant followed by exposure to the sun whereby UVA irradiations are given $2 \mathrm{~h}$ after administration of 8-methoxypsoralen, a photosensitizer [19]. In present study, we evaluate anti melanogenesis property of $\beta$-sitosterol (2), visnadine (3), khellin (4), $\beta$-sitosterol glucoside (5), khellol (7) and cimifugin (9). The yield of other compounds is very low having no further amounts for biological evaluation. These compounds were assayed by using B16 melanoma cells in order to evaluate the inhibition of melanin formation and cell viability at their maximum solubility. For khellin and $\beta$-sitosterol, the maximum solubility was $20 \mu \mathrm{g} / \mathrm{mL}$ while for other compounds the maximum solubility was 40 $\mu \mathrm{g} / \mathrm{mL}$. In Figure 2, the inhibition of these compounds on melanin formation in B16 melenoma cells was shown at various concentrations.

Taking into consideration of the cytotoxicity to cell lines, the most active compound exhibiting melanin synthesis inhibition $(\sim 37 \%)$ and at the same time with low cytotoxicity ( $\sim 1 \%$ ) was khellin (4) at $20 \mu \mathrm{g} / \mathrm{mL}$, followed by khellol (7) ( $\sim 28 \%$ inhibition) but with a toxic effect to some extent ( $\sim 20 \%$ cytotoxicity). Visnadine (3) at concentration of 40 and $20 \mu \mathrm{g} / \mathrm{mL}$ showed cytotoxicity on B16 melenoma cells rather than melanin formation inhibition, but at a concentration of $10 \mu \mathrm{g} / \mathrm{mL}$, it showed about $8 \%$ melanin inhibition with less toxicity. Also ci-

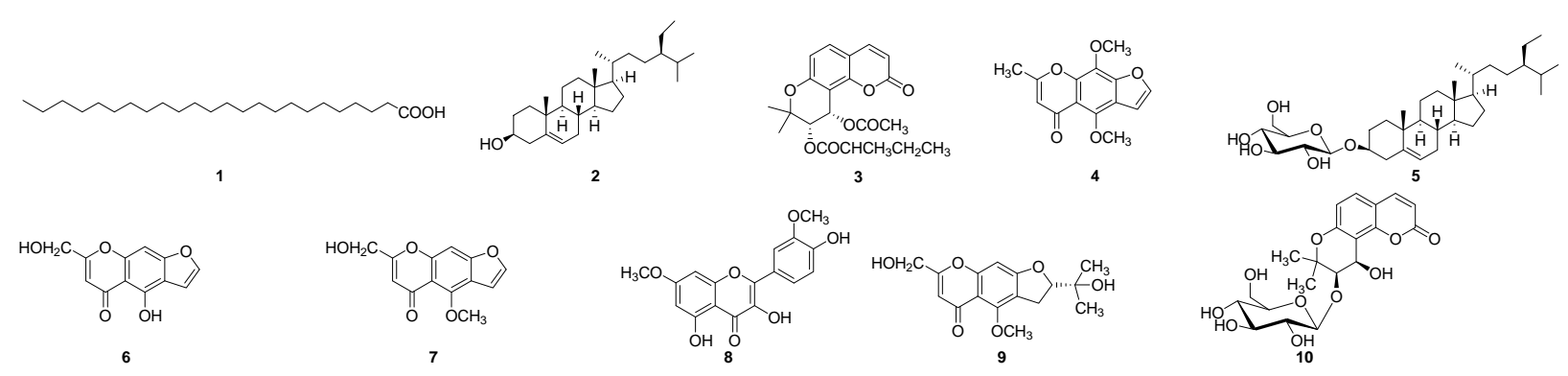

Figure 1. Chemical structures of isolated compounds.

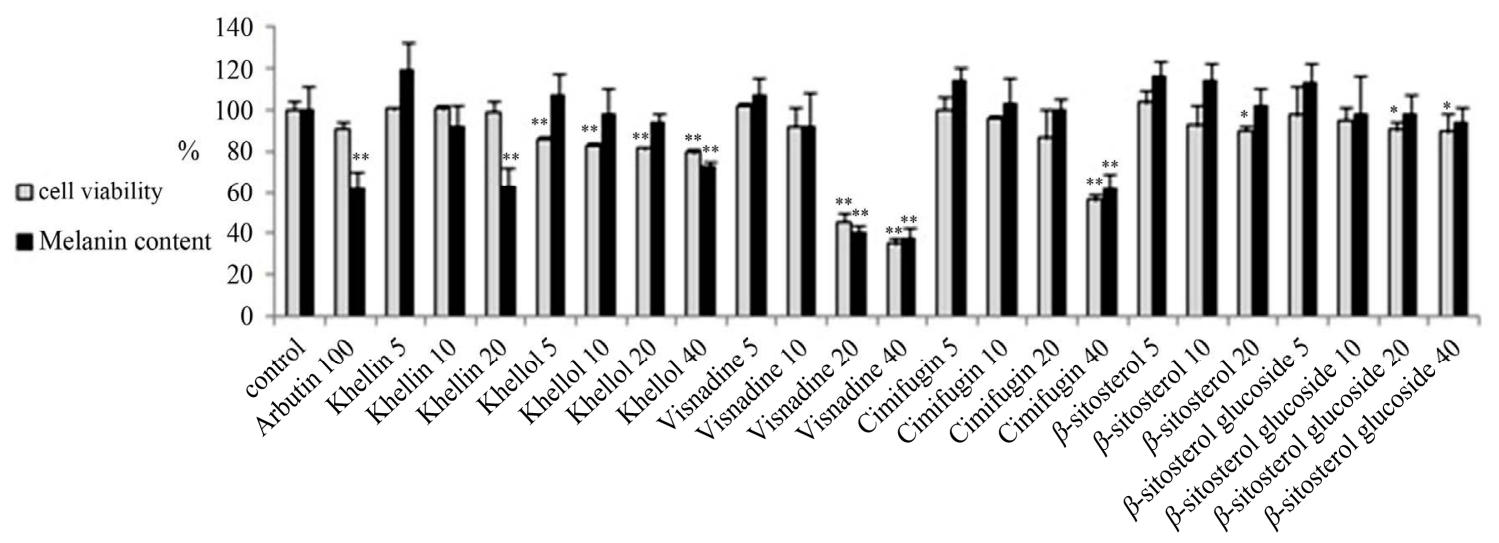

Figure 2. Chemical structures of isolated compounds. 
mifugin (9) at concentration of $40 \mu \mathrm{g} / \mathrm{mL}$ showed cytotoxicity on B16 melenoma cells rather than melanin formation inhibition; $\beta$-sitosterol (2) and $\beta$-sitosterol glucoside (5) had no effect on melanin inhibition.

Previously, khellin was reported to have some biological effects such as smooth muscle relaxant [20] and prevention of stone formation associated with hyperoxaluria [8], while in our study we concluded that khellin (4) is a promising compound which could be useful for treating hyperpigmentation, as a skin-whitening agent with less toxicity even than the standard drug arbutin. To the best of our knowledge, we obtained this compound from the waste of $A$. visinaga which caused a serious problem so we can get a great beneficial from these waste.

\section{Acknowledgements}

The Egyptian Government is acknowledged for the fellowship support to Ahmed Adel Ashour. We are thankful to Dr. Miyamoto for optical rotation measurement.

\section{REFERENCES}

[1] M. S. Butler, "The Role of Natural Product Chemistry in Drug Discovery," Journal of Natural Product, Vol. 67, No. 12, 2004, pp. 2141-2153. http://dx.doi.org/10.1021/np040106y

[2] G. M. Cragg, D. J. Newman and K. M. Snader, "Natural Products in Drug Discovery and Development," Journal of Natural Product, Vol. 60, No. 1, 1997, pp. 52-60. http://dx.doi.org/10.1021/np9604893

[3] F. K. El-Fiky, R. P. Remmel and E. J. Staba, "Ammi Visinaga: Somatic Embryo Induction and Furanochrommone Production in Embryos, Seedlings and Plants," Planta Medica, Vol. 55, No. 5, 1989, pp. 446-451. http://dx.doi.org/10.1055/s-2006-962061

[4] K. Günaydin and N. Beyazit, "The Chemical Investigation on the Ripe Fruits of Ammi visinaga (Lam.) Lamarck Growing in Turkey," Natural Product Research, Vol. 18, No. 2, 2004, pp. 169-175. http://dx.doi.org/10.1080/14786410310001608091

[5] H. Jouad, M. Maghrani and M. Eddouks, "Hypoglycemic Effect of Aqueous Extract of Ammi visnaga in Normal and Streptozotocin-Induced Diabetic Rats," Journal of Herbal Pharmcotherapy, Vol. 2, No. 4, 2002, pp. 19-29. http://dx.doi.org/10.1080/J157v02n04 03

[6] J. Duarte, F. Perez-Vizcaino, A. Torres, A. Zarzuelo, J. Jimenez and J. Tamargo, "Vasodilator Effects of Visnagin in Isolated Rat Vascular Smooth Muscle," European Journal of Pharmacology, Vol. 286, No. 2, 1995, pp. 115-122. http://dx.doi.org/10.1016/0014-2999(95)00418-K

[7] J. Lee, J. Jung, S. Park, S. Park, Y. Sim, S. Kim, T. Ha and H. Suh, "Anti-Inflammatory Effect of Visnagin in Lipopolysaccharide-Stimulated BV-2 Microglial Cells," Archives of Pharmacal Research, Vol. 33, No. 11, 2010, pp. 1843-1850.

http://dx.doi.org/10.1007/s12272-010-1117-1
[8] P. Vanachayangkul, K. Byer, S. Khan and V. Butterweck, "An Aqueous Extract of Ammi visnaga Fruits and Its Constituents Khellin and Visnagin Prevent Cell Damage Caused by Oxalate in Renal Epithelial Cells," Phytomedicine, Vol. 17, No. 8-9, 2010, pp. 653-658. http://dx.doi.org/10.1016/j.phymed.2009.10.011

[9] M. Antunes, S. Pina Dos Santos and F. Brito, "Coumarins from Ammi huntii," Colloques-Institut National de la Recherche Agronomique, Vol. 69, 1995, pp. 305-306.

[10] Y. Selim and N. Ouf, "Anti-Inflammatory New Coumarin from the Ammi majus L.," Organic and Medicinal Chemistry Letter, Vol. 2, 2012, pp. 1-4. http://dx.doi.org/10.1186/2191-2858-2-1

[11] R. Bencheraiet, H. Kherrab, A. Kabouche, Z. Kabouche and M. Jay, "Flavonols and Antioxidant Activity of Ammi visnaga L. (Apiaceae)," Records of Natural Products, Vol. 5, No. 1, 2011, pp. 52-55.

[12] E. T. Arung, K. Shimizu and R. Kondo, "Structure Activity Relationship of Phenyl Substituted Polyphenols from Artocarpus heterophyllus as Inhibitors of Melanin Biosynthesis in Cultured Melanoma Cell," Chemistry \& Biodiversity, Vol. 4, No. 9, 2007, pp. 2166-2171. http://dx.doi.org/10.1002/cbdv.200790173

[13] M. M. Amer, S. H. El-Sharkawy, F. M. Abdel Bar and A. A. Ashour, "Phytochemical Investigation of Unused Parts of Hibiscus sabdariffa," Journal of American Science, Vol. 8, No. 12, 2012, pp. 29-35.

[14] Y. Ikeshiro, I. Mase and Y. Tomita, "Dihydropyranocoumarins from Roots of Peucedanum japonicum," Phytochemistry, Vol. 31, No. 12, 1992, pp. 4303-4306. http://dx.doi.org/10.1016/0031-9422(92)80463-O

[15] A. Abou-Mustafa, M. Saleh, A. Elgamal, M. Shalaby and H. Duddeck, "A Further Contribution to the $\gamma$-Pyrone Constituents of Ammi visnaga Fruits," Planta Medica, Vol. 56, No. 1, 1990, p. 134

http://dx.doi.org/10.1055/s-2006-960912

[16] P. Agrawal, R. Thakur and M. Bansal, "Carbon-13 NMR of Flavonoids," Elsevier Science Publishing Company Inc., New York, 1989.

[17] H. Sonnenberg, M. Kaloga, N. Eisenbach and K. Froemming, "Isolation and Characterization of an Angular-Type Dihydropyranocoumaringlycoside from the Fruits of Ammi visnaga (L.) LAM. (Apiaceae)," Zeitschrift fur Naturforschung C: Journal of Biosciences, Vol. 50, No. 9-10, 1995, pp. 729-731.

[18] P. Cao, X. Pu, S. Peng, X. Zhang and L. Ding, "Chemical Constituents from Cimicifuga foetida," Journal of Asian Natural Products Research, Vol. 7, No. 2, 2005, pp. 145149. http://dx.doi.org/10.1080/1028602042000204081

[19] R. Roelandts, "Photo (chemo) Therapy for Vitiligo," Photodermatology, Vol. 19, No. 1, 2003, pp. 1-4. http://dx.doi.org/10.1034/j.1600-0781.2003.00003.x

[20] R. Kory, A. Townes, R. Mabe, E. Dorris and G. Meneely, "Drug Evaluation in Angina Pectoris: Khellin, Heparin, Peritrate," American Heart Journal, Vol. 50, No. 2, 1955, pp. 308-321. http://dx.doi.org/10.1016/0002-8703(55)90326-4 